\title{
Determination of Peroxyacetylnitrate (PAN) in Unpolluted Areas
}

B. VIERKORN-RUDOLPH, J. RUDOLPH and S. DIEDERICH Institut für Chemie 3: Atmosphärische Chemie der Kernforschungsanlage Jülich GmbH, P.O. Box 1913, D.5170 Jülich, F.R.G.

PAN is not only important as toxic product of photochemical pollution but may also act as an important reservoir for nitrogen oxides outside polluted areas.

However, only very few measurements of PAN in unpolluted areas have been reported in the literature, mainly as a result of the lack of simple, reliable and sufficiently sensitive techniques for the measurements of PAN in background air.

In our paper we will describe a completely automatic gas chromatographic system. Without enrichment it allows the determination of PAN with a lower limit of detection of $\approx 10 \mathrm{ppt}$. Combined with an adsorptive enrichment procedure at low temperature detection limits of less than $1 \mathrm{ppt}$ are possible. At these low concentrations, a complete separation from possible interfering atmospheric constituents (e.g. halocarbons) is necessary. This is achieved by separation on a $1 \mathrm{~m}$ long glass column, i.d. $2 \mathrm{~mm}$, packed with $5 \%$ PEG 400 on Chromosorb W HP $80 / 100$ mesh at ambient temperature. For field measurements-especially for in sitk measurements on board of airplanes-a special light weight gas chromatograph with a peltier cooled oven was developed.

KEY WORDS: Peroxyacety! nitrate measurements by gas chromatography, adsorptive enrichment of PAN, automatic instrument for PAN measurement at ppt levels.

\section{INTRODUCTION}

Peroxyacetylnitrate is not only important as a toxic product of photochemical poliution but may also act as an important reservoir 
B. VIERKORN-RUDOLPH, J, RUDOLPH AND S. DIEDERICH

for Jogen oxides outside of polluted areas. To da.? most of the available PAN measurements are from more or less polluted urban and rural environments. ${ }^{1,2,3,4,5,6}$ Only very few measurements of PAN in unpolluted areas have been reported. ${ }^{7,8}$ This is mainly a result of the lack of simple, reliable and sufficiently sensitive techniques for the measurement of PAN in background air. In the following paper we will describe completely automatic gas chromatographic systems suitable for the determination of PAN at levels of a few parts per trillion or even below.

\section{EXPERIMENTAL, RESULTS AND DISCUSSION}

A schematic drawing of the experimental set-up is shown in Figure 1. The 10-port valve (I) serves as injection valve and for backflushing the column. During the backflush time sample air is pumped through the sample loop. The 4-port valve (II) allows to separate the sample loop from the carrier gas stream. This diminishes the tailing

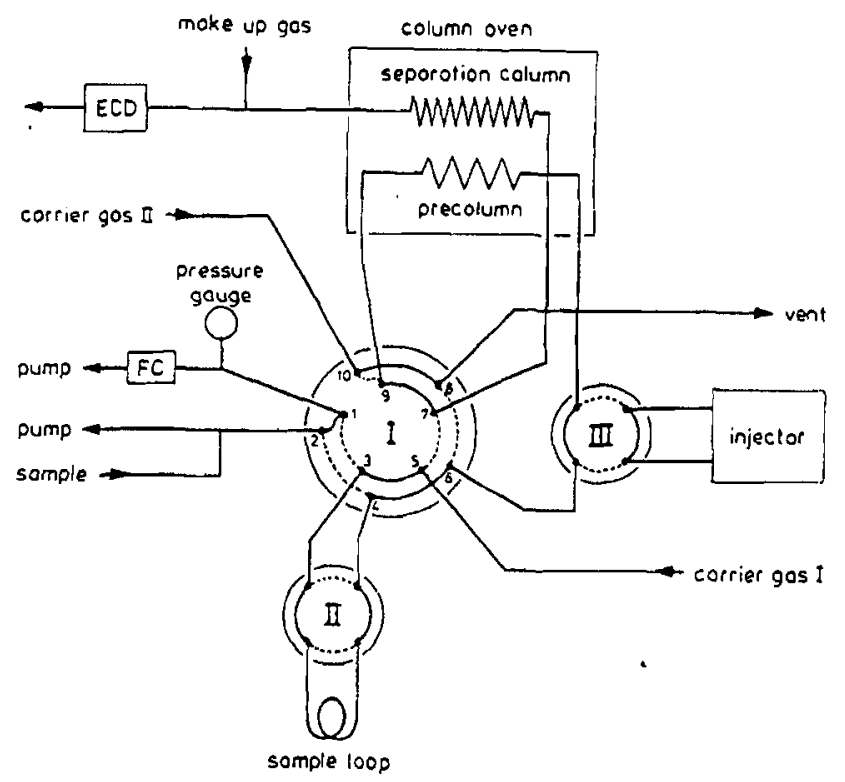

FIGURE I Schematic drawing of the sample injection system. Explanation see text.
PEROXY AETYLNITRATE (PAN) IN UNPOLLUTED AREAS . ,

of the extremely large peaks especially the tailing of $\mathrm{t}$. Xxygen peak. The multiport valves I and II are pneumatically actuated switching valves. The gas flows for the pneumatic actuators of the multiport valves are switched by solenoid valves. These solenoid valves are controlled by a time programable microprocessor.

The manually actuated 4-port valve (III) allows liquid injection by means of a usual gas chromatographic injector. Switching the 4-port valve causes the carrier gas to flow through the injector. Otherwise the carrier gas flow passes only the 4-port valve to prevent memory effects or losses of sample in the liquid injector. The multiport valves which we use are stainless steel valves with PTFE rotor. The connections between the different parts of the inlet system are made by $1 / 16^{\prime \prime}$ stainless. steel tubes to minimize dead volumes and the contact time between the samples and the walls of the connecting lines.

Pump I serves for flushing the inlet line, a $4 \mathrm{~mm}$ i.d. PTFE-tube, with outside air. The flow rate is $1-21 / \mathrm{min}$ to prevent losses of PAN in the inlet line. This allows to use length of $10-20 \mathrm{~m}$ without observable sample degradation. Part of this air stream is used for flushing the sample loop (pump II). The flow rate of $100-300 \mathrm{ml} / \mathrm{min}$ of air is regulated by a flow controller. The sample loop is made of glass with an i.d. of $4 \mathrm{~mm}$ and a volume between 10 and $20 \mathrm{~cm}^{3}$.

For separation we use a $1 \mathrm{~m}$ long, $2 \mathrm{~mm}$ i.d. glass tube, packed with 5\% PEG 400 on Chromosorb W HP 80/100 mesh. The precolumn is simply a shorter version of the separation column with a length of $30 \mathrm{~cm}$. The separation temperatures are between 15 and $20^{\circ} \mathrm{C}$. To allow operation of the chromatograph at temperatures slightly below ambient conditions, the instrument (Sichromat I, Siemens $A G$ ) is equipped with a heat exchanger; this heat exchanger is connected to a cryostat which is maintained at $-30^{\circ} \mathrm{C}$.

For detection of PAN a $10 \mathrm{mCi}(0.37 \mathrm{GBq}) \mathrm{Ni} 63$ electron-capture detector (ECD) is used. Detector temperature is $55-58^{\circ} \mathrm{C}$. The flow rate through the column is between 40 and $60 \mathrm{ml} / \mathrm{min}$. The flow rate of the make-up gas for the ECD is about $10 \mathrm{ml} / \mathrm{min}$.

For enrichment of PAN we use dry ice-ethanol as cooling agent. The temperature of this dry ice-ethanol mixture is $\approx-78^{\circ} \mathrm{C}$. The sample loop is the same as described above with a volume of $20 \mathrm{~cm}^{3}$ The flow rate through the sample loop is $100 \mathrm{ml} / \mathrm{min}$, the enrichment time $5-20 \mathrm{~min}$, thus PAN is concentrated from $500-2000 \mathrm{~cm}^{3}$ of air. 
B. VIERKORN.RUDOLPH, J. RUDOLPH AND S. DIEDERICH

FC ') situ infight measurements of PAN a special hpact light weight gas chromatograph was built. The gas sampling inlet system is in principle the same as described above with the exception that $1 / 8^{\prime \prime}$ stainless steel tubes are used for the connections between the different valves to diminish the pressure drop in the system. At the maximum flight level of usual jet aircrafts the air pressure outside the cabin is only 0.2 bar or even below. At these low inlet pressures, the use of $1 / 16^{\prime \prime}$ tubing would not allow the fow rates of the sample gas which are necessary for the optimum operation of the instrument. The oven is replaced by an isolated aluminium box which is thermostated by peltier elements. For enrichment of PAN the above mentioned dry ice-ethanol mixture is used. This mixture is kept in an isolated aluminium container which is moved up and down pneumatically allowing automatic cooling of the sample loop. The whole equipment, inlet system, oven, cooling bath, strip chart recorder, power supply for the peltier elements, detector electronics, timer etc. are installed in a rack with an overall height of $125 \mathrm{~cm}$, a width of $65 \mathrm{~cm}$ and a depth of $80 \mathrm{~cm}$. The weight of the complete instrument is about $80 \mathrm{~kg}$. This instrument also operates completely autonatic.

\section{Calibration}

The calibration of our system is carried out with PAN-conccntrations which correspond to mixing ratios which are expected for senti-rural areas. These mixing ratios are obtained by diluting the $400 \mathrm{ppm}$ PAN mixture which is delivered by TNO (Central Organisation for Applied Scientific Research in the NetherlandsUtrecht) by a factor of $10^{5}-10^{6}$. The dependence of the peak height from the thus obtained mixing ratios of PAN is shown in Figure 2. The standard deviation for the determination of PAN is $2 \%$ for concentrations above $1 \mathrm{ppb}$ increasing to $6 \%$ at $0.5 \mathrm{ppb}$. The $3 \sigma$ detection limit is $10 \mathrm{ppt}$.

\section{Field calibration}

It is known that PAN decomposes irreversibly during storage ${ }^{12.13}$ at ambient temperatures. Thus direct calibration of PAN during field experiments is difficult to achieve. Therefore we use n-propylnitrate as externall standard. $\mathrm{N}$-propylnitrate hals a similar detection sensi-

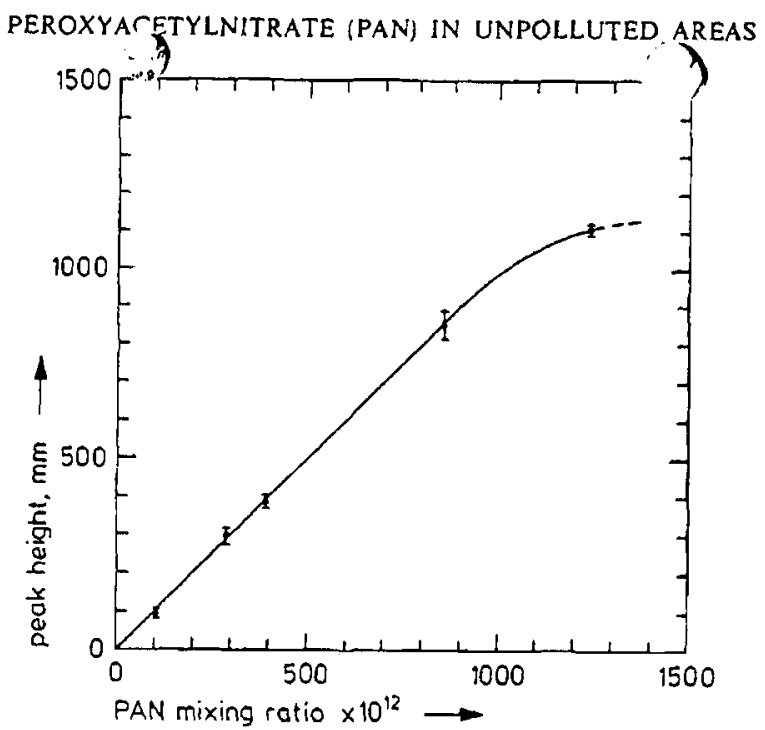

FIGURE 2 Calibration curve for PAN, sample volume $20 \mathrm{~cm}^{3}$. The points with error bars represent average and stadard deviation for at least $S$ measurements of the sinne air mixture.

livity and retention time as PAN. On the other hand n-propylnitrate is a liquid which is quite stable in the dark. It is very easy to dilute n-propyl nitrate to appropriate concentrations with suitable solvents such as n-heptane. The detection sensitivity of PAN and n-propylnitrate is compared at known concentrations of both compounds to determine a conversion factor PAN to n-propylnitrate. Based on this factor the sensitivity, instrument performance, calibration etc. can be checked and any changes be corrected by calibrating the instrument with n-propylnitrate in the field.

\section{Separation and identification}

The main conditions which should be observed for the determination of PAN are the following:

a) Complete separation of PAN from all other possible interfering compounds. 
R VIERKORN-RUDOLPH, J. RUDOLPH AND S. DIECYFRICH

b) .... separation temperatures of $20^{\circ} \mathrm{C}$ or below shiuld be used to minimize the loss of PAN on the column.

c) The sample volume should be relatively large to obtain low detection limits for PAN.

The instrument described above fully meets these requirements. The PAN peak in chromatograms from ambient air samples is identified by its retention time. This identity is checked by increasing the detector temperature-for PAN an increase of the ECD temperature results in a decrease of sensitivity. The quality of the separation can be tested by decomposing PAN with potassium hydroxide.

In Figure $3 \mathrm{a}$ and $\mathrm{b}$ two chromatograms of ambient air samples which were determined within half an hour are shown, one with and one without a "KOH-scrubber" in the inlet line. This "KOH. scrubber" consists of a glass or PTFE tube with $\approx 4 \mathrm{~mm}$ i.d. of $10 \mathrm{~cm}$ to $50 \mathrm{~cm}$ length. The length of this tube depends on the desired air flow rate through this tube. It is packed with glass beads of $2 \mathrm{~mm}$ size coated with potassium hydroxide. The PAN peak in Figure $3 a$ corresponds to a mixing ratio of $1.55 \mathrm{ppb} P A N$, in Figure $3 \mathrm{~b}$ (air sampled through a $\mathrm{KOH}$-scrubber in the inlet line, no other changes being made) no significant peak for PAN can be recognized. This demonstrates that PAN can be quantitatively (more than $99 \%$ ) removed by potassium hydroxide from air. This is an importan point since it is -in addition to a chromatographic separation with good resolution of the different peaks-a further evidence for the "purity" of the PAN peak.

\section{PAN enrichment}

The enrichment of PAN in a coiled glass tube of $4 \mathrm{mmi}$.d. and $20 \mathrm{~cm}^{3}$ volume at dry ice temperature $\left(-78^{\circ} \mathrm{C}\right)$ is reproducible within $10 \%$ accuracy and nearly quantitative $(\approx 90 \%)$. During sample desorption, the temperature of the sample loop must not exceed $20^{\circ} \mathrm{C}$, otherwise substantial thermal decomposition of PAN can occur. Due to this rather limited thermal stability it is not advisable to use packed adsorption tubes (regardless of the packing) for the concentration of PAN from ambient air samples: at moderate temperatures below $20^{\circ} \mathrm{C}$ desorption of PAN from most surfaceswith the exception of very smooth surfaces such as glass-will be
PEROXYA
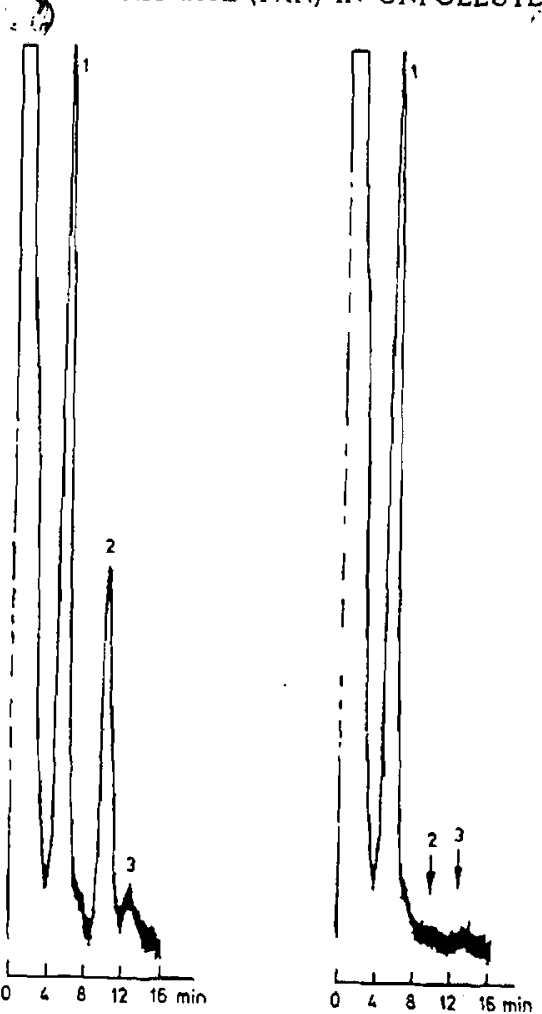

F1GURE 3 Chromatograms from air samples, Jülich, 20. February 1984, late morning a. without PAN removal, the PAN peak (2) corresponds to a mixing ratio of $1.5 \mathrm{ppb}$. b. less than 30 minutes later but with a "KOH-scrubber" for PAN removal in the inlet line, no other changes wete made.

slow, resulting in broad, tailing peaks, at higher temperatures thermal decomposition of PAN will occur. The air flow rate through the adsorption loop should be in the order of $100 \mathrm{~cm}^{3} \mathrm{~min}$. ${ }^{-1}$ If the flow rate is higher, the adsorption efficiency will be reduced, at much lower flow rates PAN may partly decompose in the injection system. It is essential to keep the adsorption loop at or below a temperature of $-75^{\circ} \mathrm{C}$ during PAN enrichment. Even slightly higher tempera- 
reproducibility

\section{Performance of the instruments}

The methods described above have successfully been used for measurements of PAN in semi-rural and rural areas as well as for the determination of vertical and horizontal profiles of PAN up to altitudes of nearly $12 \mathrm{~km}$. Figure 4 shows the time dependence of the PAN mixing ratio for a period of three days in March 1984 at the $\mathrm{KFA}$ Jülich. These measurements were made without preconcen. tration of PAN by injecting $20 \mathrm{~cm}^{3}$ of air onto the column.

It can be seen that this method is adequate for measuring PAN even outside polluted areas. The sensitivity, reproducibility and reliability of this instrument is sufficient for the determination of PAN in remote and semi-remote areas of continental Germany without entichment of PAN. The situation is different for the measurement of vertical profiles. The mixing ratios of PAN outside the planetary boundary layer are generally rather low and-as a result of the rather unfavourable conditions for the inflight operation

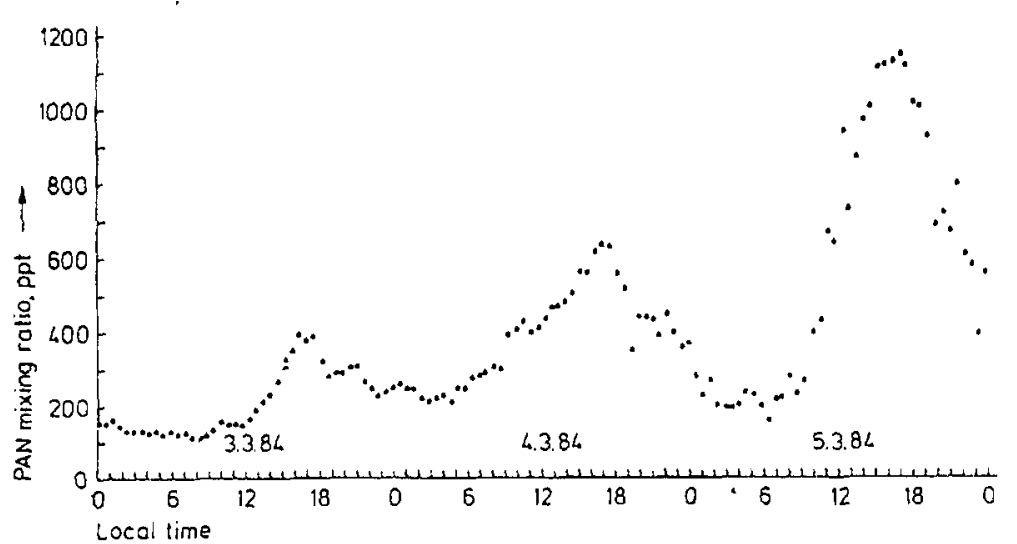

FIGURE 4 Variation of the atmospheric mixing tatio of PAN near Jülich between Mareh the 3rd and 5th. 1984. Each point represents one measurement. These daltil are part of a longer series of measurements noidde at the KFA Jülich in eitly 1984.

\section{PEROX ACTYLNITRATE (PAN) IN UNPOLLUT MAREAS} of a gaschromatograph-the lower limit of detection ror PAN under these conditions is by a factor of about 3 higher than for ground based instruments.

Therefore it seems necessary to combine the chromatographic measurement with a preconcentration of PAN such as described above or other. ${ }^{7,10,11}$ The use of dry ice as cooling agent for the enrichment of PAN from ambient air has considerable advantages over the use of liquid nitrogen or argon as far as logistics (storage, availability, handling etc.) are concerned. In Figure 5 a chromatogram of an inflight measurement of PAN is shown. The PAN peak corresponds to a mixing ratio of $30 \mathrm{ppt}$. It can be seen that even considerably lower PAN mixing ratios would still show peaks which could easily be evaluated. Indeed, throughout a campaign of more than three weeks where measurements of PAN (and other atmospheric trace constituents) between $65^{\circ} \mathrm{N}$ and $60^{\circ} \mathrm{S}$ up to altitudes of

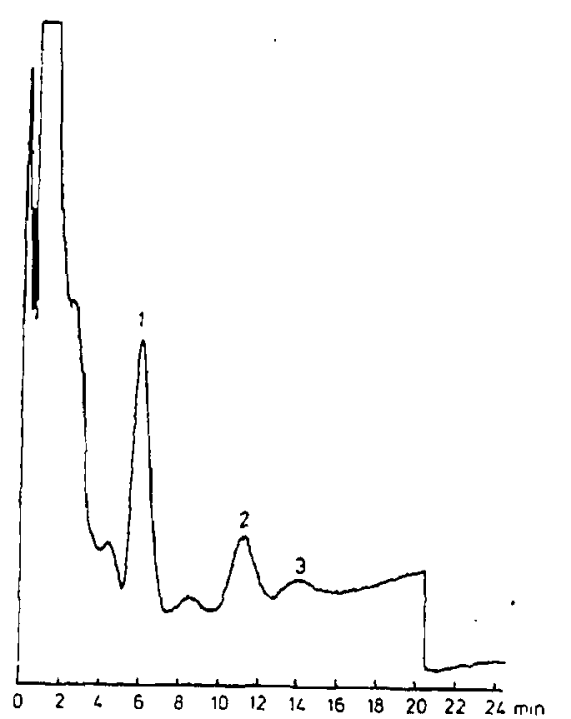

FIGURE 5 Chromatogram of a sample enriched from $2 \mathrm{dm}^{3}$ of air at $-78.5^{\circ} \mathrm{C}$. The PAN peak corresponds to a mixing ratio of $30 \mathrm{ppt}$. This measurement was made inflight on June the 7 th 1984,21 : I $5 \mathrm{~h}$ UT between $40^{\circ} \mathrm{N} / 64^{\circ} \mathrm{W}$ and $38^{\circ} \mathrm{N} / 64^{\circ} \mathrm{W}$ at an altitude range from 19000 to $27000 \mathrm{nt}$ 

problems of such field campaigns, the instrument was operational for more than $90 \%$ of the flights. The result of these measurements wil be presented elsewhere, a presentation and discussion of these data would be beyond the scope of this paper

\section{Acknowledgement}

This work was supported by the Germany Ministry of Science and Technology.

\section{References}

1. E. R. Stephens, P. L. Hanst, R. C. Doerr and W. E. Scolt, Ind. Engng. Chem. 48 , 1498 (1956)

2. E. R. Stephens, Adv. Envir. Sci. 1, 119 (1969)

3. S. A. Penkett, F. J. Sandalls and J. G. Lovelock, Atmos. Environ. 9, 139 (1975).

4. W. A. Lonnemann, J. J. Bufalini and R. L. Seila, Environ. Sci. Technol. 10, 374 (1976).

5. H. Nieboer and J. van Ham, Almos. Environ. 10, 115 (1976).

6. T. Nielsen, U. Samuelsson, P. Grennielt and E. L. Thomsen, Nature, Lond. 293, 553 (1981).

7. H. B. Singh and L. J. Salas, Atmos. Environ. 17, 1507 (1983).

8. H. B. Singh and L. J. Salas, Nature, 302, 326 (1983).

9. J. Löbel, V. Wipprecht and U. Schurath, Staub-Reinhak. Luft 40, 243 (1980).

10. U. Schurath, U. Kortmann and S. Glavas, Proc. 3rd European Symp. "PhysicoChemical Behaviour of Atmospheric Pollutants", Varese, 10-12.4.84, 99 (1984).

11. H. Meyrahn, J. Hahn, G. Helas, P. Warneck and S. A. Penkell, Proc. 3rd European Symp. "Physico-Chemical Behaviour of Atmospheric Pollutants", Varese, 10-12.4.84, 109 (1984).

12. P. Bruckmann and W. Mülder, Schrifienreihe der Landesanstalt für Immissionsschut : des Lamdes Nordrhein-West falen 47, 30 (1979).

13. R. A. Cox and M. J. Roffey, Environ. Sci. Technol. 11 (9), 900 (1977)

\section{Analysis of Toxaphene}

\section{HARUN PARLART}

Gesellschaft für Strahlen. und Umweltforschung mbH München, Institut für Okologische Chemie D-8050 Freising-Attaching, F.R.G.

Toxaphene, a widely and chlorinated hydrocarbon insecticide produced by chlorination of camphene, consists of a poorly defined mixture of at least 180-190 substances. Most of these conform the formulars $\mathrm{C}_{10} \mathrm{H}_{18-n} \mathrm{Cl}_{n}$ and $\mathrm{C}_{10} \mathrm{H}_{16-n} \mathrm{Cl}_{n}$, where $n$ is $6-10$. Although the chromatographic behaviour of the toxaphene components is extremely similar, seven components have been isolated up to now, six of which are hepta- to decachlor derivatives of bornane. In the following work, isolation and identification of these compounds with the help of spectroscopical methods are described and their behaviour under biotic and abiotic conditions are studied. The experiments shown, that toxaphene is slowly to rapidly degraded in various environmental systems

KEY WORDS: Toxaphene, spectroscopical characterization, residue analysis.

\section{INTRODUCTION}

The development of new plant protection agents during the past decade had among others the essential aim to produce new substances for the replacement of banned compounds or compounds suffering from severely curtailed manufacture. These include, e.g., DDT and cyclodiene insecticides. On the other hand, there are preparations which have been known as insecticides for a long time and whose fields of application, especially after the ban on DDT, were expanded strongly. One preparation in this group is toxaphene.

†Presented at the 14th Annual Symposium on the Analytical Chemistry of Pollutants, Barcelona. November 2i-23, 1984. 